\title{
Artificial photosynthesis via two-electron conversion: Photochemical oxygenation sensitized by ruthenium porphyrins with water as both electron and oxygen atom donor
}

\author{
Haruo Inoue $\ddagger$, Shigeaki Funyu, Yutaka Shimada, and \\ Shinsuke Takagi
Department of Applied Chemistry, Graduate Course of Engineering, Tokyo Metropolitan University, Japan Science and Technology, Minami-ohsawa, Hachiohji, Tokyo 192-0397, Japan

\begin{abstract}
Recent progress in the field of artificial photosynthesis is reviewed. Among various approaches to oxidizing the water molecule, attention has been focused on the two-electron chemical conversion processes mediated by metallo-porphyrins upon visible light irradiation. Photochemical oxygenation reactions such as the epoxidation of alkenes sensitized by ruthenium(II) porphyrins with water as both electron and oxygen atom donor have been found. $\mathrm{Ru}$ porphyrin induces highly efficient two-electron oxidation of water with a quantum yield of $60 \%$ to form an epoxide from the alkene with high selectivity. The water molecule serves as both an efficient electron and oxygen atom donor in the reaction, in which the oxygen atom of water is incorporated in a useful product, i.e., epoxide.
\end{abstract}

Keywords: artificial photosynthesis; oxidation of water; epoxidation; ruthenium porphyrin; photochemical oxygenation; photochemistry; oxygenation.

\section{INTRODUCTION}

Artificial photosynthesis by visible light is one of the most desirable systems to be realized by humankind. For the past several decades, extensive efforts have been made in the field of artificial photosynthesis, which involves photochemical reactions to convert light energy into chemical energy via endoergonic processes.

Recent efforts on photoredox systems that can induce actual chemical reactions have focused much attention on the reduction terminal end of the photoredox systems rather than on the oxidation terminal end. Efficient hydrogen evolution [1] and even carbon dioxide reduction [2] have been reported. The possibility of artificial photosynthesis is, however, still questionable in spite of enormous efforts. In this article, several novel approaches to artificial photosynthesis are reviewed on the basis of the present status of the field.

\footnotetext{
*Paper based on a presentation at the XX ${ }^{\text {th }}$ IUPAC Symposium on Photochemistry, 17-22 July 2004, Granada, Spain. Other presentations are published in this issue, pp. 925-1085.

¥Corresponding author: E-mail: inoue-haruo@c.metro-u.ac.jp
} 
a)

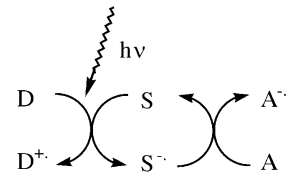

b)

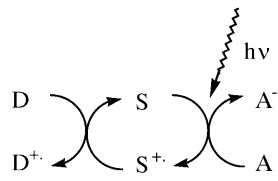

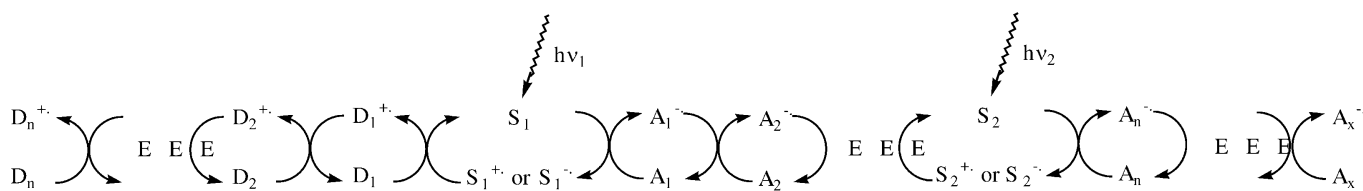

Scheme 1 (a) Single photon-induced electron transport through a reductive quenching, (b) single photon-induced electron transport through an oxidative quenching, (c) conceptual propagation of electron transport driven by two photons: the $Z$-scheme.

\section{SUBJECTS NOT YET RESOLVED FOR ARTIFICIAL PHOTOSYNTHESIS}

When reports published during the past several decades directly or indirectly correlated with artificial photosynthesis are surveyed, it becomes clear that various crucial aspects of the following topics still remain to be resolved before artificial photosynthesis can be realized.

- $\quad$ efficient light-harvesting system

- $\quad$ efficient electron transfer

- control of chemical behavior of ion radicals

- $\quad$ incorporation of the water molecule as an electron donor

- $\quad$ systemization of the artificial photosynthetic system

\section{Efficient light-harvesting system}

One of the most impressive findings in the field of photosynthesis of the past decades would be the amazingly beautiful alignment of the chromophore molecules in the natural photosynthetic center, which provides an efficient light-harvesting pathway leading to selective energy flow into the reaction center [3]. This finding has been a source of substantial stimulation and has induced many challenging approaches to mimic the molecular alignment (Fig. 1). 


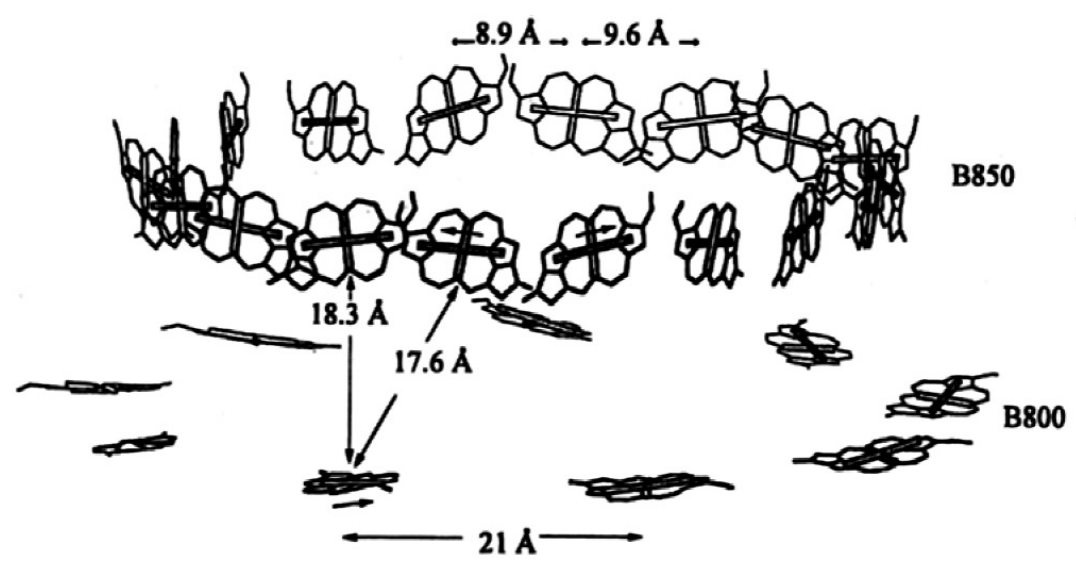

Fig. 1 The structure of LH2 antenna complex in Rps. acidophila bacteria [3].

Tamiaki et al. have revealed that solvent induced aggregation among chlorophyll-type molecules through intermolecular hydrogen bonding can simulate well the absorption spectrum of natural photosynthetic pigments, affording a suggestive approach of how to align chromophore molecules (Fig. 2) [4].

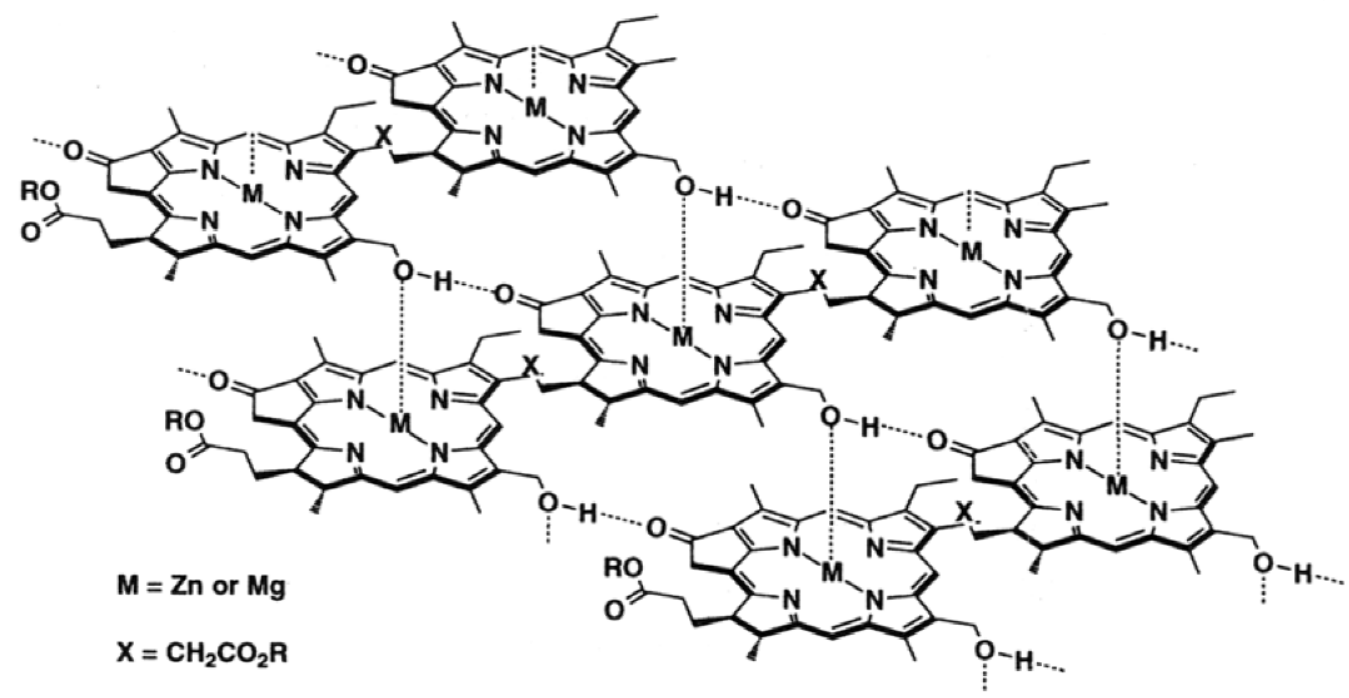

Fig. 2 The supramolecular structure for self-aggregates of metallochlorin [4].

Another interesting approach of aligning molecules by utilizing a pattern of electrical charges on nanolayered inorganic compounds such as clays has appeared [5-7]. High-density adsorption of cationic porphyrins up to $100 \%$ cation exchange capacity without any aggregation has been attained. This type of alignment termed a "size-matching effect" is akin to that of an elegantly aligned paving stone on flat ground. Efficient energy transfer was observed on an adsorbed clay surface (Fig. 3) [8]. 


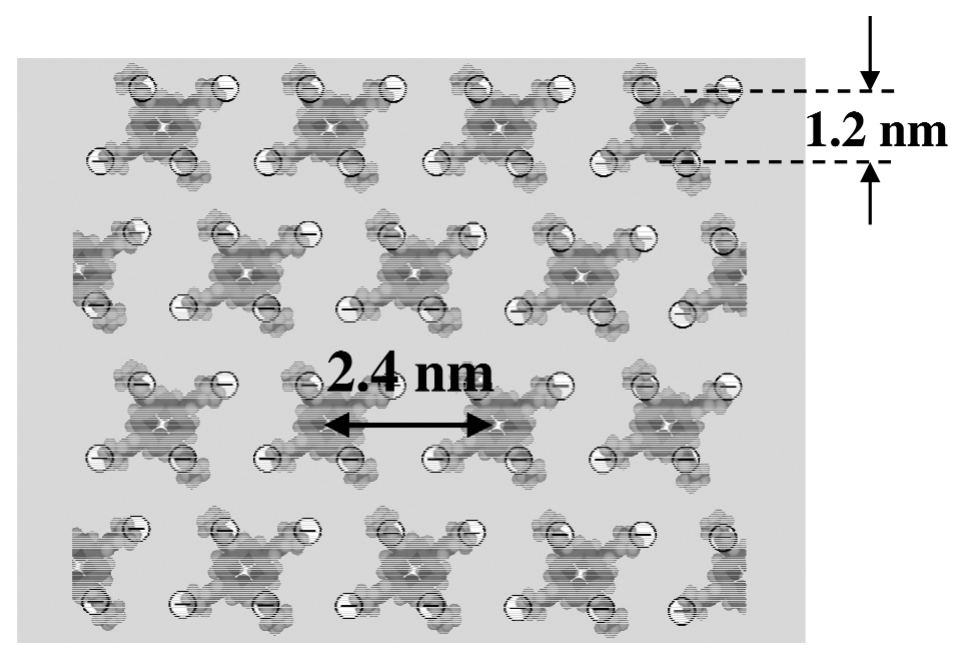

Fig. 3 Schematic view of clay-porphyrin complex (size-matching effect) [6].

An interesting polymeric J-aggregate formation by solvent-induced precipitation has also been reported (Fig. 4) [9].
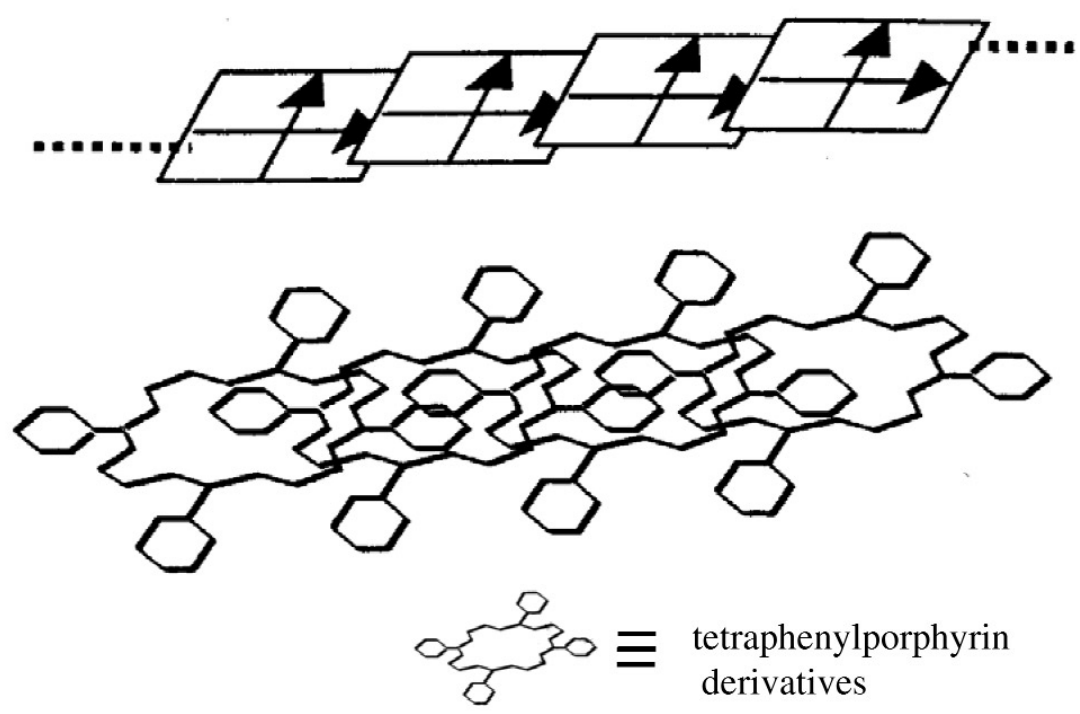

Fig. 4 Proposed structure of the porphyrin J-aggregate [9].

These approaches promise to lead to getting a grip on acquiring novel methodology for the construction of efficient light-harvesting units. On the basis of these trends, the next challenging target to be resolved for light-harvesting systems would be how to couple efficiently among the light-harvesting units and reaction centers, so that a selective irreversible energy flow can be attained.

\section{Efficient electron transfer}

On the basis of tremendous studies on electron-transfer processes, many efficient light-induced electron-transfer reactions have been reported [10-12], and charge separation leading to long lifetimes of the resultant ion pairs has been attained (Fig. 5) [13]. Chemical reactions promoted by efficient energy 
transfer through chain-type mechanism have also been reported [14,15]. The subject to be resolved, however, is to obtain an efficient electron-transfer reaction that induces a totally endoergonic reaction at both oxidation and reduction terminal ends upon visible light irradiation in the actual artificial photosynthetic system.

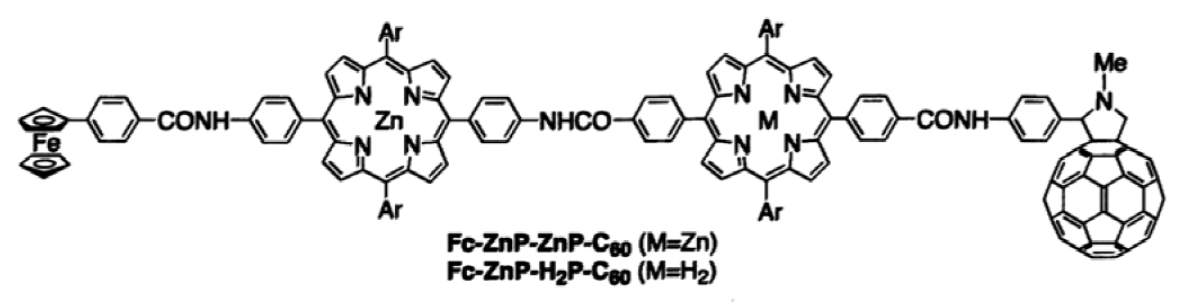

$$
\mathrm{Fc}^{+}-\mathrm{ZnP}-\mathrm{ZnP}-\mathrm{C}_{60}{ }^{-} \rightarrow \mathrm{Fc}-\mathrm{ZnP}-\mathrm{ZnP}-\mathrm{C}_{60} \quad \mathrm{k}=0.64 \mathrm{~s}^{-1}
$$

Fig. 5 A molecular tetrad allowing efficient energy storage for $1.6 \mathrm{~s}$ at $163 \mathrm{~K}$ [13].

\section{Control of chemical behavior of ion radicals}

As is easily understood in Schemes 1a-1c, a cation radical is formed at the oxidation terminal end, while the reduction terminal one produces an anion radical. In the more sophisticated $z$-scheme (Scheme 1c), the ion radical can abstract or transfer electrons to form another ion radical species. The conceptual propagation of ion radicals through the electron transport system should be largely dependent upon whether or not the ion radicals are stable enough within the time scale of the subsequent electron transfer. Thorough understanding of the chemical behavior of the radical ions and the related reactive intermediates would, thus, be indispensable in designing and constructing actual artificial photosynthetic systems. Amazingly long lifetimes of reactive intermediates, carbenes, have been reported recently [16]. These reports strongly encourage workers in the field of reactive intermediates to take on the challenge of actively controlling these unstable intermediates, which is one of the most desirable targets to be reached.

\section{Incorporation of the water molecule as an electron donor}

For artificial photosynthesis, how to utilize the water molecule as an ideal electron donor should be one of the most crucial problems to be resolved. In spite of the tremendous efforts in the past several decades, the incorporation of the water molecule as an electron donor in artificial photosynthetic systems had long been questionable, since it is one of the most oxidation-resistant ones. Activation of water has long been considered to be one of the most difficult subjects. Only a very few reactions, however, can actually be coupled in the oxidative terminal end of photoredox reactions [17-21]. Among various approaches for the oxidation of water, a semiconductor such as $\mathrm{TiO}_{2}$ has been one of the most promising candidates. Ultraviolet light irradiation of $\mathrm{a} \mathrm{TiO}_{2}$ electrode connected with a Pt electrode in an aqueous electrolyte induces oxygen evolution from the $\mathrm{TiO}_{2}$ surface and hydrogen evolution from the Pt surface [22]. This phenomena (i.e., the photochemical splitting of water) is often referred to as the "Honda-Fujishima effect". The finding of the Honda-Fujishima effect on the photochemical splitting of water by $\mathrm{TiO}_{2}$ [22] afforded a strong impact and has led to recent progress in the field [23,24]. Even though the light energy utilized for the excitation of $\mathrm{TiO}_{2}$ is discouragingly limited to that in the ultraviolet region, due to the large band gap (3.0 eV for rutile and $3.2 \mathrm{eV}$ for anatase) [25], interesting reports have recently appeared that visible light can drive similar reactions on semiconductors such as $\mathrm{TiO}_{2-x} \mathrm{~N}_{x}$ and $\mathrm{In}_{1-x} \mathrm{Ni}_{x} \mathrm{TaO}_{4}[23,24]$. Dye-sensitized solar cells using nanocrystalline $\mathrm{TiO}_{2}$ that can uti- 
lize visible light energy have greatly improved the energy conversion efficiency and have attracted much attention [26].

On the other hand, metal complexes have been another potential candidates for the water-splitting reaction. A binuclear Ru complex has been reported to give rise to an elegant four-electron oxidation of water (Fig. 6) [17h,17i,27], and binuclear manganese complexes have also been reported to exhibit a similar reaction [28].
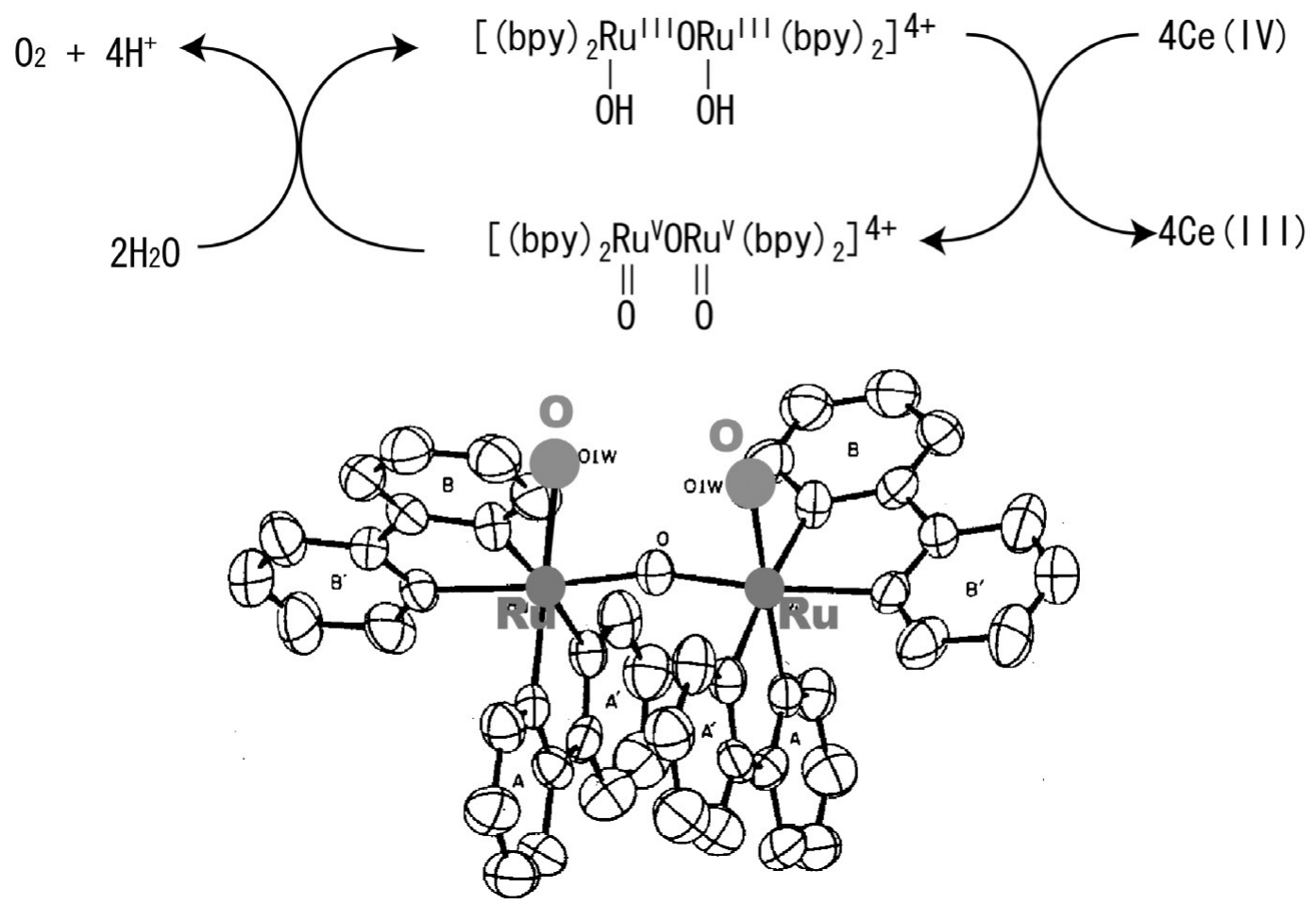

Fig. 6 Four-electron oxidation of water by binuclear metal complex [27b].

The interesting reactions, however, that have thus far been reported are driven by chemical or electrochemical oxidation upon the metal complexes and have not yet been connected with photoreactions. The difficulties in designing a photochemical reaction system with metal complexes for water oxidation involve problems to be solved, such as (1) how the water molecule could be incorporated in the electron donor system of the photoreaction, (2) how the highly specific stereochemical arrangement among the metal complexes could be achieved for the four-electron oxidation processes, and (3) how self-decomposition reactions ascribed to the high oxidation state of the metal complexes could be avoided. The oxidation of water should involve one of the following:

- a one-electron process [29],

- a two-electron one, or

- a multielectron one [17].

The one-electron process, particularly the one-electron oxidation of the hydroxide ion, requires a rather high oxidation potential $(>2.0 \mathrm{~V})$, and the resultant hydroxide radical is too reactive to be handled. The multielectron one, for example, the four-electron process, requires a highly specific stereochemical arrangement, as described above, although the thermodynamic requirement for the process is less stringent. To avoid the difficulties of these two processes, among the actual photoreactions, we have recently focused our attention on the two-electron oxidation of water, which also has a mild thermo- 
dynamic requirement, sensitized by several high-valent metalloporphyrins [18-20]. Our recent approach shall be surveyed in a later section. How to get the highly specific stereochemical arrangement among molecules would also be a crucial target to be resolved. A series of the nanolayered compounds such as the clay minerals that can align molecules on their surfaces would provide one of the promising microenvironments for the purpose [5-8].

\section{Systemization of artificial photosynthetic systems}

As is well understood in natural photosynthetic systems, each functional unit, such as the light-harvesting unit and the reaction centers, is adequately aligned and doped in the protein environment. These appear to be reasonably organized with respect to each other within the membrane to exert an efficient electron transport from the water molecule to carbon dioxide. The artificial photosynthetic system that we are trying to approach, however, does not necessarily require complete mimicking of the natural system, but the essential concept of the system is strongly suggested to be one of the ideal methodologies. Systemization of the artificial photosynthetic system would be the final target to be challenged in this field, and now we, scientists, may be on the starting line for the approach.

\section{TWO-ELECTRON OXIDATION OF WATER UPON VISIBLE LIGHT IRRADIATION}

When we focus our attention on the splitting of water to evolve hydrogen upon visible light irradiation, there could be two options as indicated in eqs. 1 and 2.

$$
\begin{array}{ll}
\mathrm{H}_{2} \mathrm{O} \longrightarrow \begin{array}{l}
\text { Two-electron } \\
\text { reduced product }
\end{array} & \mathrm{H}_{2} \\
\mathrm{H}_{2}+\mathrm{S} \longrightarrow \mathrm{O}_{2} \\
\begin{array}{l}
\text { Four-electron } \\
\text { oxidized product }
\end{array} \\
\begin{array}{l}
\text { Two-electron } \\
\text { reduced product }
\end{array} & \begin{array}{l}
\mathrm{SO} \\
\text { Two-electron } \\
\text { oxidized product }
\end{array}
\end{array}
$$

The process in eq. 1 has attracted exclusive attention from scientists who have been involved in artificial photosynthesis, since oxygen evolution should provide direct evidence of water-oxidation, which is the most essential feature of natural photosynthesis. Hydrogen is a two-electron reduced species, while oxygen as the second product is a four-electron oxidation product from the water molecule. Simultaneous formation of these two reaction products with different numbers of electrons required for their formation, thus, should not be possible in a single process. From the viewpoint of the number of electrons involved in each process, eq. 1 indicates that rather complicated plural processes are required. On the other hand, the reaction in eq. 2 appears to have a more reasonable number of electrons involved. The reaction products are hydrogen and an oxygenated species, $\mathrm{SO}$, where the substrate, $\mathrm{S}$, serves as an oxygen atom acceptor. Both products require the same number of electrons for their formation: hydrogen is a two-electron reduction product from the protons, while SO requires two-electron oxidation from water and the substrate, S. We have, thus, focused our attention on the process in eq. 2 and have found that metal-complexes serve as two-electron conversion media upon visible light-initiated oneelectron oxidation of the complexes.

Metal-complexes themselves are typical supramolecular systems, which are composed of moderately plural intermolecular interactions such as coordination bonds. They have inherently plural aspects for chemical behavior [30,31]. From the photochemical viewpoint, metal-complexes have long been subjected to studies on (1) photochemical electron transfer and or (2) energy transfer, since interatomic distances can easily be adjusted and estimated in terms of the coordination bonds [31]. Ligand-localized photochemistry is a third aspect that has attracted much attention [31]. The most attractive and crucial aspect, however, should be the ligand-metal coordination bond, which undergoes two-electron con- 
version either in oxidative addition of ligand to the metal center or in heterolytic bond cleavage. Photochemical oxygenation sensitized by metallo-porphyrins with water as both electron and oxygen atom donor is based on the two-electron conversion mediated by the central metal in the complex as described below (Fig. 7).

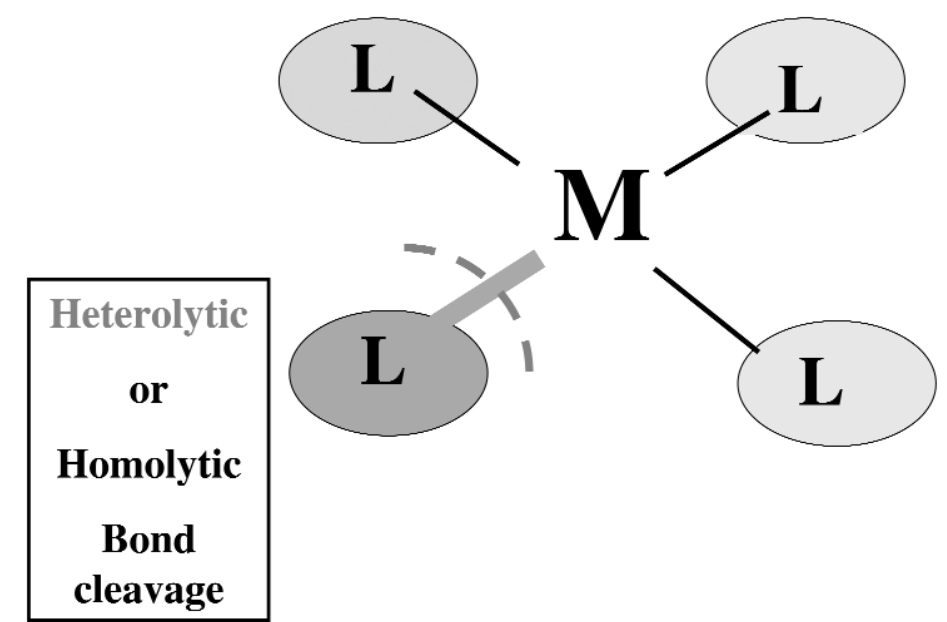

Fig. 7 Photochemistry of metal complexes and two-electron conversion through heterolytic cleavage of ligand-metal bond.

\section{Photochemical oxygenation sensitized by metallo-porphyrins with water as both electron and oxygen atom donor as a typical example of two-electron conversion}

One of the key factors in designing photo-redox systems should be the redox potentials of the sensitizers, which absorb visible light; specifically, the oxidation potentials are critical in terms of whether or not the water molecule is actually activated by incorporation in the electron donor systems. Photochemical redox reactions sensitized by metallo-porphyrins have been studied extensively thus far, while high-valent metallo-porphyrins have attracted rather less attention [32]. The oxidation potentials of metallo-porphyrins are known to be mainly dependent on the valence state of the central metal ions [33]: A higher valence state induces a higher oxidation potential. The relatively high oxidation potential of the high-valent metallo-porphyrins is expected to be rather favorable for the incorporation of water in the electron donor systems. From these viewpoints, we have examined photochemical redox reactions sensitized by high-valent metallo-porphyrins. Efficient irreversible electron transport from triphenylphosphine as an electron donor to methylviologen as an electron acceptor was observed upon visible light irradiation of tin(IV) tetraphenylporphyrin $\left(\mathrm{Sn}^{\mathrm{IV}} \mathrm{TPP}\right)(1.60 \mathrm{~V}$ vs. SHE) [34]. Antimony $(\mathrm{V})$ tetraphenylporphyrin $\left(\mathrm{Sb}^{\mathrm{V}} \mathrm{TPP}\right)$ with its higher oxidation potential $(1.92 \mathrm{~V}$ vs. SHE) induced the hydroxylation of an alkene through the cation radical of triphenylphosphine generated by reductive quenching of the triplet porphyrin [18c,18d]. Very interestingly, $\mathrm{Sb}^{\mathrm{V}}$ TPP also induced an epoxidation reaction of an alkene upon visible light irradiation under alkaline conditions without triphenylphosphine [18a,18b]. The hydroxide ion enhanced the photochemical epoxidation significantly.

An experiment using ${ }^{18} \mathrm{O}$ indicated that the oxygen atom originated from the water molecule, strongly suggesting the incorporation of hydroxide ion or water into the electron donor cycle, in which the alkene served as the oxygen atom acceptor. The reactivity, however, was rather modest mainly owing to the low net electron-transfer efficiency in the excited triplet state of the porphyrin as presumed by a rather complicated reaction mechanism, which involved a deprotonation of the axial ligand, the hydroxyl group, in the excited triplet state (Fig. 8) [18b]. 


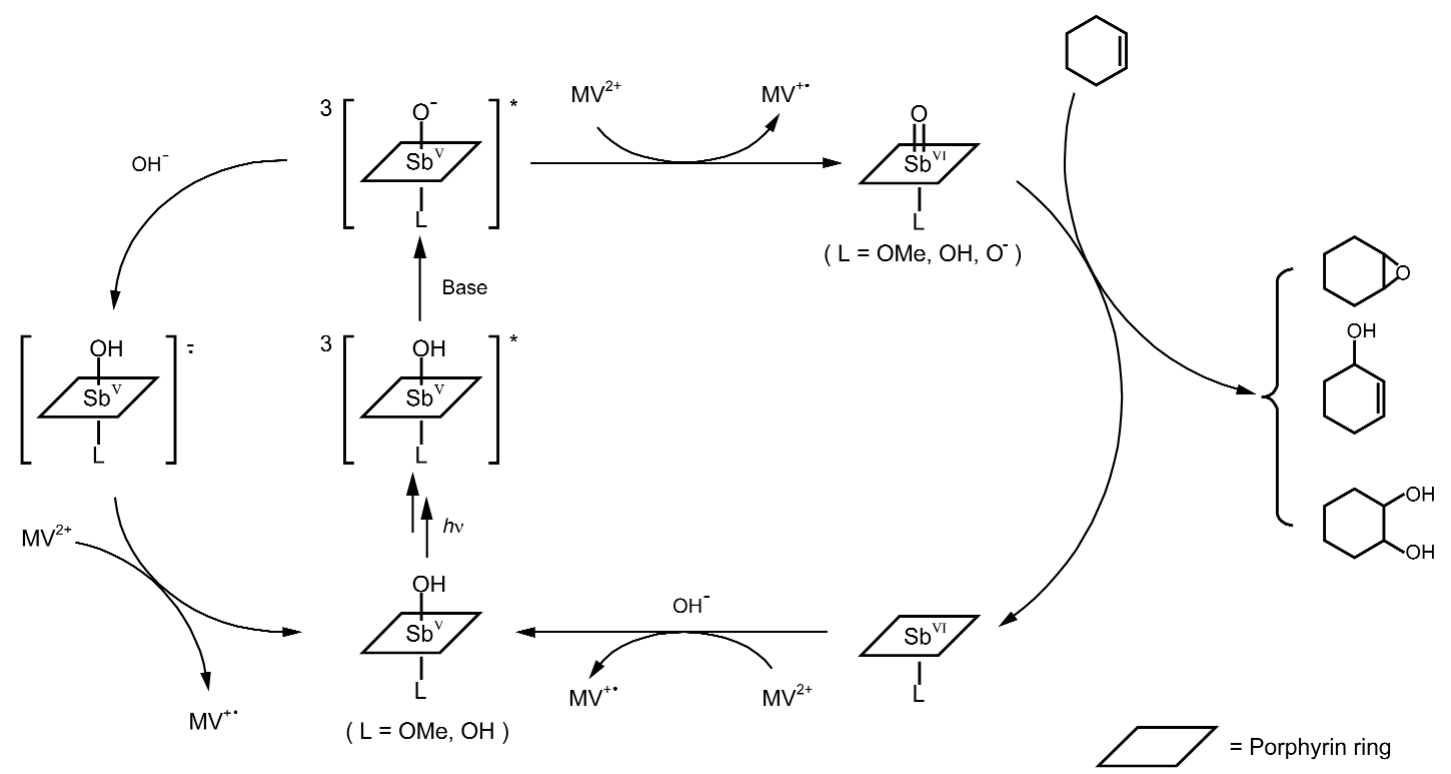

Fig. 8 Proposed reaction scheme for the photochemical oxygenation of alkene sensitized by $\mathrm{Sb}^{\mathrm{V}} \mathrm{TPP}$ [18b].

An efficient reductive quenching by hydroxide ion was found to compete with the oxidative electron transfer to the electron acceptor, methylviologen [18b,20b]. A more efficient electron acceptor, $\mathrm{K}_{2} \mathrm{PtCl}_{6}$, was thus examined, and it exhibited a substantial improvement of the oxidative electron transfer to the acceptor. An enormous enhancement of the reactivity by $\mathrm{K}_{2} \mathrm{PtCl}_{6}$ was first observed in the case of dimethoxy-coordinated $\mathrm{Sb}^{\mathrm{V}} \mathrm{TPP}$, which provides no opportunity for deprotonation of the axial ligand [19]. Hole transfer from the resultant cation radical of dimethoxy-coordinated $\mathrm{Sb}^{\mathrm{V}} \mathrm{TPP}$ led to the efficient formation of cyclohexenol from cyclohexene with quantum yield up to 0.4. Another possible route of oxygenation of alkene should arise here when the axial ligand is exchanged from a methoxyl group to a hydroxyl group. Coordination of the hydroxyl group with activation of the axial ligand by one-electron oxidation of the parent metal complex could be the most direct and favorable method of incorporating the water molecule into the electron donor cycle. In addition to the hole transfer from the cation radical of $\mathrm{Sb}^{\mathrm{V}} \mathrm{TPP}$ to the alkene, which leads to its hydroxylation through the resultant cation radical of the alkene, another oxygenation reaction could be expected to be induced from the deprotonated species of the cation radical $\mathrm{Sb}^{\mathrm{V}} \mathrm{TPP}$ [20]. The former route does not entail a water oxidation at all, while the latter is an actual two-electron oxidation route involving a water molecule. The deprotonation of the axial hydroxyl group ligated on the one-electron oxidized $\mathrm{Sb}^{\mathrm{V}} \mathrm{TPP}^{+}$would form an oxotype complex as indicated in Fig. 9. The one-electron abstraction and dissociation of one proton from the hydroxy-coordinated metal complex would afford a species that is isoelectronic with the metal oxocomplex, which is a species that is quite similar to those well known in the model reaction systems of the P-450 enzyme, an efficient oxygen-transfer species.
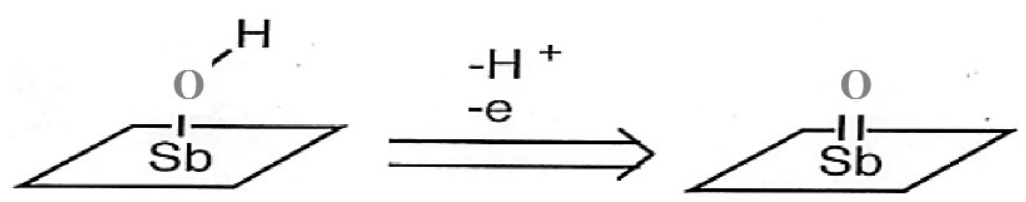

Fig. 9 Activation of water moelcule on metal complex through (1) axial coordination, (2) one-electron oxidation, (3) deprotonation, and (4) two-electron conversion by metal ion as electron pool. 
Visible light irradiation of hydroxy-coordinated $\mathrm{Sb}^{\mathrm{V}} \mathrm{TPP}$, in the presence of $\mathrm{K}_{2} \mathrm{PtCl}_{6}$ as an electron acceptor and cyclohexene as an oxygen acceptor under alkaline conditions, actually induced formation of the epoxide, cyclohexeneoxide, along with cyclohexenol as expected [20] (Fig. 10).

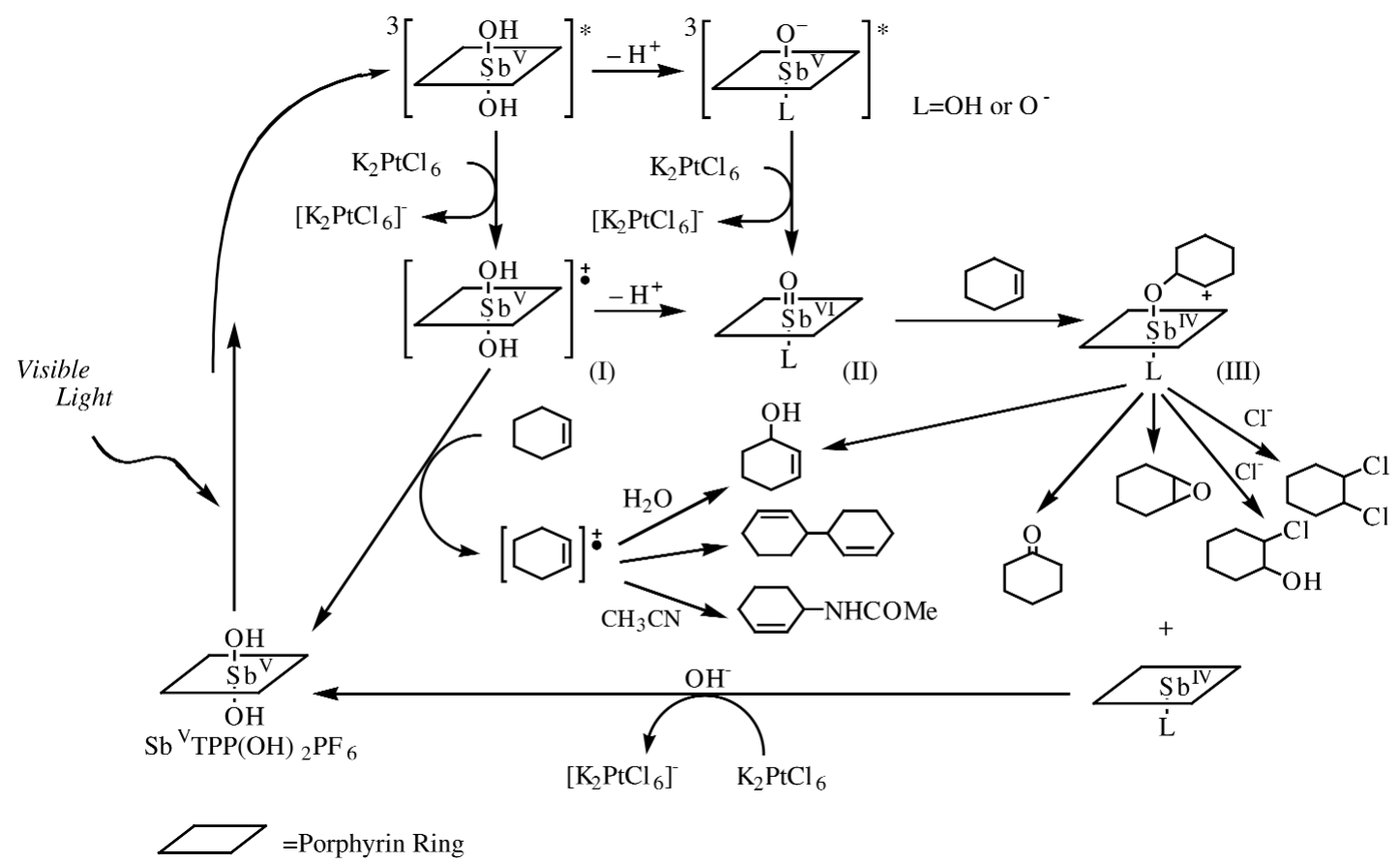

Fig. 10 Photochemical oxygenation of alkene sensitized by $\mathrm{Sb}^{\mathrm{V}} \mathrm{TPP}(\mathrm{OH}){ }_{2} \mathrm{PF}_{6}$ with $\mathrm{K}_{2} \mathrm{PtCl}_{6}$ as an electron acceptor [20]. tor [34].

$\mathrm{Sn}^{\mathrm{IV}} \mathrm{TPP}$ also exhibited a similar photochemical epoxidation with $\mathrm{K}_{2} \mathrm{PtCl}_{6}$ as an electron accep-

Although the reaction mechanisms for the high-valent metallo-porphyrins are rather complicated because of their high oxidation potentials, which allows them to have dual reaction routes of forming oxygenated species as described above, transition-metal porphyrins having less positive oxidation potential such as $\mathrm{Ru}(\mathrm{II})$ tetramesitylporphyrin $\left[\mathrm{Ru}^{\mathrm{II}} \mathrm{TMP}(\mathrm{CO})\right]\left(E_{\mathrm{ox}}=1.03 \mathrm{~V}\right.$ vs. SHE) would be expected to exert a more efficient epoxidation upon visible light irradiation as anticipated from their P-450 model reactions, which are initiated by strong oxidizing agents without light irradiation [35-37]. In very good accordance with expectation, visible light irradiation of $\mathrm{Ru}^{\mathrm{II}}(\mathrm{CO}) \mathrm{TMP}$ as a sensitizer, in the presence of $\mathrm{K}_{2} \mathrm{PtCl}_{6}$ as an electron acceptor and cyclohexene as an oxygen atom acceptor in the de-aerated alkaline aqueous acetonitrile, actually induced a highly selective epoxidation of alkenes with water as both an oxygen donor and a two-electron donor [38]. The net chemistry of the reaction can be expressed by eq. 3 .

$$
\mathrm{C}_{6} \mathrm{H}_{10}+\mathrm{H}_{2} \mathrm{O}+\mathrm{Pt}(\mathrm{IV}) \mathrm{Cl}_{6}{ }^{2-} \frac{h v}{\mathrm{Ru}^{\mathrm{II}} \mathrm{TMP}(\mathrm{CO})} \mathrm{C}_{6} \mathrm{H}_{10} \mathrm{O}+\mathrm{Pt}(\mathrm{II}) \mathrm{Cl}_{4}{ }^{2-}+2 \mathrm{HCl}
$$

An experiment with $\mathrm{H}_{2}{ }^{18} \mathrm{O}$ revealed that an ${ }^{18} \mathrm{O}$ atom was quantitatively incorporated into the oxygenated products under de-aerated conditions. When $\mathrm{H}_{2}{ }^{18} \mathrm{O}$ ( $32.2 \%$ content $)$ was used in the photoreaction, incorporation of ${ }^{18} \mathrm{O}$ into the oxygenated products was $32.2 \%$ in cyclohexene oxide and $31.8 \%$ in 2-cyclohexenol, respectively. This clearly indicates that a water molecule serves as an oxy- 
gen donor in the photochemical oxygenation reaction. Photoreactions with other alkenes under alkaline conditions also afforded the epoxide as almost an exclusive product, as indicated in Table 1.

Table 1 Photochemical epoxidation of alkenes sensitized by $\operatorname{Ru}^{\mathrm{II}} \mathrm{TEMP}(\mathrm{CO})^{\mathrm{a}}$.

\begin{tabular}{|c|c|c|c|c|}
\hline Alkene & $\begin{array}{l}{[\mathrm{KOH}] /} \\
10^{-3} \mathrm{M}\end{array}$ & Products (selectivity/\%) & $\begin{array}{c}\text { Quantum } \\
\text { yield } / 10^{-2}\end{array}$ & $\begin{array}{c}E_{\mathrm{OX}} / \mathrm{V} \text { vs. } \\
\mathrm{SHE}^{\mathrm{b}}\end{array}$ \\
\hline & 1.5 & & 16 & 2.08 \\
\hline & 0.0 & & 7.0 & 2.08 \\
\hline & 0.0 & & - & 2.08 \\
\hline & 1.5 & $(0.3)$ & 11 & 2.17 \\
\hline & 1.5 & (0.1) & 5.9 & 2.30 \\
\hline & 1.5 & & 0.27 & 1.81 \\
\hline & 1.5 & 100) & 0.16 & 1.92 \\
\hline & 1.5 & & 0.14 & 2.71 \\
\hline & 1.5 & & - & 2.00 \\
\hline
\end{tabular}

${ }^{\mathrm{a}}\left[\mathrm{Ru}^{\mathrm{II}} \mathrm{TMP}(\mathrm{CO})\right]=1.0 \times 10^{-5} \mathrm{M},\left[\mathrm{K}_{2} \mathrm{PtCl}_{6}\right]=5.0 \times 10^{-4} \mathrm{M}$, [Alkene] $=1.0 \times 10^{-3} \mathrm{M}$ in degassed $\mathrm{CH}_{3} \mathrm{CH}_{2} \mathrm{H}_{2} \mathrm{O}(9: 1 \mathrm{v} / \mathrm{v} \%)$. Visible light $(420 \mathrm{~nm})$ was irradiated.

bef. 30.

$\mathrm{c}_{20} \mathrm{~s}$.

d540 min.

cis-Stilbene was converted into its epoxide, cis-stilbene oxide, without forming trans-stilbene oxide. Interestingly, trans-stilbene, however, did not exhibit any reactivity. Contrary to the results obtained here, a dioxo-complex of $\mathrm{Ru}$ octaethylporphyrin, $\mathrm{Ru}^{\mathrm{VI}} \mathrm{OEP}(\mathrm{O})_{2}$, which has only a slight steric hindrance around the metal center, has been reported to afford both the cis- and trans-form of the epoxide from cis-stilbene and even exhibit a reactivity for trans-stilbene, in a study of P-450 model systems in which the alkene was converted to the corresponding epoxide by catalytic action of the ground-state $\mathrm{Ru}$ porphyrins [39]. In the present photochemical system with $\mathrm{Ru}^{\mathrm{II}} \mathrm{TMP}$, which has substantial steric hindrance in the vicinity of the metal center due to the methyl groups in the ortho-positions on the mesosubstituted phenyl ring, trans-stilbene, with its extended molecular structure, might not be able to sufficiently access the metal center of the Ru complex, as observed in P-450 model systems [40,41]. The lack of formation of the isomerized form, trans-stilbene oxide, from cis-stilbene strongly suggests that a concerted, stereoregulative mechanism is operating in the photochemical epoxidation.

The overall view of the reactivities of alkenes examined here does not necessarily show a direct correlation between the reactivities and the oxidation potentials of the alkenes (Table 1), but other factors such as steric ones could also be controlling the reactivity, which supports the idea that the reaction proceeds in a concerted manner on the metal center of the complex. The highest quantum yields 
for the photochemical epoxidation turned out to be 0.60 for the formation of cyclohexene oxide from cyclohexene, with a selectivity of $94.4 \%$, and 0.40 for norbornene oxide formation, with $99.7 \%$ selectivity. This reaction serves as a typical example of a photoreaction that can incorporate a water molecule both as an oxygen atom donor and two-electron donor.

Under neutral conditions, an efficient build-up of the cation radical of $\mathrm{Ru}^{\mathrm{II}} \mathrm{TMP}(\mathrm{CO})$ was observed at an early stage of the photoreaction, while the addition of hydroxide ion caused a rapid reaction with the cation radical to promote a reaction with reversion to the starting $\mathrm{Ru}^{\mathrm{II}} \mathrm{TMP}(\mathrm{CO})$. A possible involvement of a higher oxidized state of $\mathrm{Ru}$ such as $\mathrm{Ru}^{\mathrm{IV}}, \mathrm{Ru}^{\mathrm{V}}, \mathrm{Ru}^{\mathrm{VI}}$ through a dismutation of the $\mathrm{Ru}^{\mathrm{III}}$ species was excluded by an experiment comparing the reaction products with those obtained from $\mathrm{Ru}^{\mathrm{VI}} \mathrm{TMP}(\mathrm{O})_{2}$ [38]. Decarbonylation of the Ru complex [42] was also proved to be invalid. A reaction mechanism involving an electron transfer from the excited triplet state of $\mathrm{Ru}^{\mathrm{II}} \mathrm{TMP}(\mathrm{CO})$ to hexachloroplatinate(IV) and subsequent formation of $\mathrm{OH}^{-}$coordinated $\mathrm{Ru}^{\mathrm{III}}$ species, leading to an oxo- $\mathrm{Ru}$ complex as the key intermediate of the photochemical epoxidation, was postulated (Fig. 11) [38].
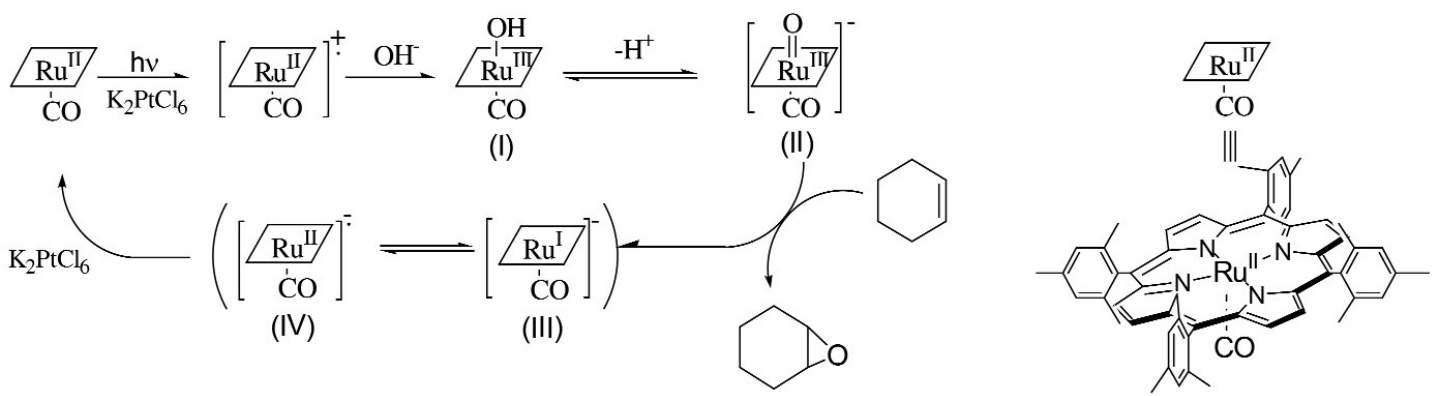

Fig. 11 Photochemical epoxidation with water as both electron and oxygen atom donor through an oxo-Ru complex as the key intermediate [38].

As can be surmised from the scheme, a hydroxide ion equilibrated with a water molecule is activated through the coordination to the metal center of the one-electron oxidized $\left[\mathrm{Ru}^{\mathrm{II}} \mathrm{TMP}(\mathrm{CO})\right]^{+}$followed by subsequent deprotonation to form the metal-oxo-complex, which exerts an oxygen atom transfer to the alkene. In the oxygen atom-transfer process, the central metal ion serves as a two-electron conversion medium: the metal-oxo-complex, $\mathrm{Ru}^{\mathrm{III}} \mathrm{TMP}(\mathrm{O})(\mathrm{CO})$ is converted into the two-electron reduced species, $\mathrm{Ru}^{\mathrm{I}} \mathrm{TMP}(\mathrm{CO})$, or the corresponding radical anion of $\left[\mathrm{Ru}^{\mathrm{II}} \mathrm{TMP}(\mathrm{CO})\right]^{-}$, as well as affording the two-electron oxidized product, the epoxide.

The photochemical epoxidation of alkene with water as both electron and oxygen atom donors discussed here can be related to reactions involving P-450 enzyme in living systems as shown in Fig. 12. 


\section{Activation of Water}

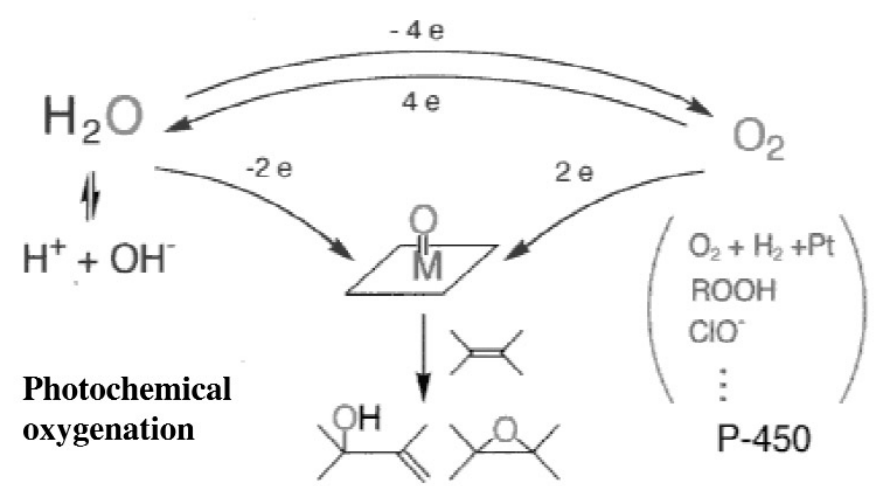

Fig. 12 Relation of the photochemical epoxidation to the P-450 enzyme model reaction.

P-450 efficiently eliminates toxic materials such as alkenes from the living body by converting them into water-soluble form through epoxidation or hydroxylation: the active center of the enzyme, iron porphyrin can utilize molecular di-oxygen and two electrons at the terminal end of the respiratory cycle to convert itself to the metal-oxo-complex and transfer an oxygen atom to the alkenes [36]. In the photochemical epoxidation discussed here, a similar metal-oxo-complex is formed through the activation of a hydroxide ion or a water molecule on the metal center of the porphyrin complex. Since the water molecule is a four-electron reduced species of molecular di-oxygen, the two electrons oxidation approaches the metal-oxo-complex, which is also accessed from a two-electron reduction from molecular di-oxygen as shown in Fig. 10.

The synthesis of epoxide compounds usually requires rather strong oxidizing agents such as hydroperoxides. From the viewpoint of synthetic methodology, this photochemical epoxidation with water as an oxygen atom donor by visible light would afford a novel synthetic method that would not require any strong oxidizing agent. When $\mathrm{H}_{2}{ }^{18} \mathrm{O}$ is used in this photochemical epoxidation, it can serve as a synthetic tool for ${ }^{18} \mathrm{O}$ labeling in the corresponding epoxides. The similar reactive species to that involved in the enzyme, P-450, promises to provide the possibility of asymmetric oxygenation as demonstrated in the living body.

\section{ACKNOWLEDGMENT}

This work has been partly supported by a Grant-in-Aid for Exploratory Research and Scientific Research on Priority Areas (417) from the Ministry of Education, Culture, Sports, Science and Technology (MEXT) of the Japanese Government.

\section{REFERENCES}

1. (a) K. Kalyanasundaram and M. Gratzel. Photosensitization and Photocatalysis Using Inorganic and Organometallic Compounds, Kluwer Academic, Dordrecht (1993) and references therein; (b) A. J. Bard and M. A. Fox. Acc. Chem. Res. 28, 141 (1995) and references therein.

2. (a) J.-M. Lehn and J.-P. Sauvage. Nouv. J. Chim. 1, 449 (1977); (b) A. Moradpour, E. Amouyal, P. Keller, H. Kagan. Nouv. J. Chim. 2 , 547 (1978); (c) A. Harriman, G. Porter, M.-C. Richoux. J. Chem. Soc. Trans. 2, 833 (1981); (d) O. Johansen, A. W. H. Mau, W. H. F. Sass. Chem. Phys. Lett. 94, 113 (1983); (e) M. Gratzel. Energy Resources through Photochemistry and Catalysis, Academic, New York (1983); (f) T. Kawai and T. Sakata. Nature 286, 474 (1980). 
3. (a) G. MacDermott, S. M. Prince, A. A. Freer, A. M. Hawthornthwaite-Lawless, M. Z. Papiz, R. J. Cogdell, N. W. Isaacs. Nature 374, 517 (1995); (b) H.-M. Wu, N. R. S. Reddy, G. J. Small. J. Phys. Chem. B 101, 651 (1997).

4. V. I. Prokhorenko, A. R. Holzwarth, M. G. Muller, K. Schaffner, T. Miyatake, H. Tamiaki. J. Phys. Chem. B 106, 5761 (2002).

5. S. Takagi, T. Shimada, T. Yui, H. Inoue. Chem. Lett. 128 (2001).

6. S. Takagi, T. Shimada, M. Eguchi, T. Yui, H. Yoshida, D. A. Tryk, H. Inoue. Langmuir 18, 2265 (2002).

7. M. Eguchi, S. Takagi, H. Tachibana, H. Inoue. J. Phys. Chem. Solid 65, 403 (2004).

8. S. Takagi, D. A. Tryk, H. Inoue. J. Phys. Chem. B 106, 5455 (2002).

9. S. Okada and H. Segawa. J. Am. Chem. Soc. 125, 2792 (2003).

10. G. J. Kavarnos and N. J. Turro. Chem. Rev. 86, 401 (1986) and references therein.

11. K. Takagi, K. Aoshima, Y. Sawaki, H. Iwamura. J. Am. Chem. Soc. 107, 47 (1985).

12. F. D. Lewis, J. R. Petisce, J. D. Oxman, M. J. Nepras. J. Am. Chem. Soc. 107, 203 (1985).

13. D. M. Guldi, H. Imahori, K. Tamaki, Y. Kashiwagi, H. Yamada, Y. Sakata, S. Fukuzumi. J. Phys. Chem. A 108, 541 (2004).

14. D. G. Whitten, P. D. Wildes, C. A. DeRosier. J. Am. Chem. Soc. 94, 7811 (1972).

15. (a) T. Arai, T. Karatsu, H. Sakuragi, K. Tokumaru. Tetrahedron Lett. 24, 2873 (1983); (b) T. Arai and K. Tokumaru. Chem. Rev. 93, 23 (1993); (c) K. Tokumaru and T. Arai. Bull. Chem. Soc. Jpn. 68, 1065 (1995).

16. E. Iwamoto, K. Hirai, H. Tomioka. J. Am. Chem. Soc. 125, 14664 (2003).

17. (a) J.-M. Lehn, J.-P. Sauvage, R. Ziessel. Nouv. J. Chim. 3, 423 (1979); (b) W. Erbs, J. Kiwi, M. Gratzel. Chem. Phys. Lett. 110, 648 (1984); (c) W. Erbs, J. Desilvestro, E. Borgarello, M. Gratzel. J. Phys. Chem. 88, 4001 (1984); (d) G. S. Nahor, S. Mosseri, P. Neta, A. Harriman. J. Phys. Chem. 92, 4499 (1988); (e) G. S. Nahor, P. Neta, P. Hambright, A. N. Thompson, Jr., A. Harriman. $J$. Phys. Chem. 93, 6181 (1989); (f) M. Kaneko, G.-J. Yao, A. Kira. J. Chem. Soc., Chem. Commun. 1338 (1989); (g) A. Harriman. J. Photochem. Photobiol. A: Chem. 51, 41 (1990); (h) T. J. Meyer. Acc. Chem. Res. 22, 163 (1989); (i) D. Geselowitz and T. J. Meyer. Inorg. Chem. 29, 3894 (1990); (j) U. Bossek, T. Weyhermuller, K. Wieghardtk, B. Nuber, J. Weiss. J. Am. Chem. Soc. 112, 6387 (1990).

18. (a) H. Inoue, M. Sumitani, A. Sekita, M. Hida. J. Chem. Soc., Chem. Commun. 1681 (1987); (b) H. Inoue, T. Okamoto, Y. Kameo, M. Sumitani, A. Fujiwara, D. Ishibashi, M. Hida. J. Chem. Soc., Perkin Trans. 1105 (1994); (c) T. Okamoto, S. Takagi, T. Shiragami, H. Inoue. Chem. Lett. 687 (1993); (d) S. Takagi, T. Okamoto, T. Shiragami, H. Inoue. J. Org. Chem. 59, 7373 (1994).

19. T. Shiragami, K. Kubomura, D. Ishibashi, H. Inoue. J. Am. Chem. Soc. 118, 6311 (1996).

20. S. Takagi, M. Suzuki, T. Shiragami, H. Inoue. J. Am. Chem. Soc. 119, 8712 (1997).

21. M. Yagi and M. Kaneko. Chem. Rev. 101, 21 (2001).

22. A. Fujishima and K. Honda. Nature 238, 37 (1972).

23. Z. Zou, J. Ye, K. Sayama, H. Arakawa. Nature 414, 625 (2001).

24. K. Sayama, K. Mukasa, R. Abe, Y. Abe, H. Arakawa. Chem. Commun. 2416 (2001).

25. A. L. Linsebigler, G. Lu, J. T. Yates. Chem. Rev. 95, 735 (1995) and references therein.

26. B. O'Regan and M. Graetzel. Nature 335, 737 (1991).

27. (a) T. J. Meyer. J. Electrochem. Soc. 7, 221C (1984); (b) S. W. Gersten, G. J. Sasmuels, T. J. Meyer. J. Am. Chem. Soc. 104, 4029 (1982); (c) J. A. Gilbert, S. W. Gersten, T. J. Meyer. J. Am. Chem. Soc. 104, 6872 (1982); (d) C. D. Ellis, J. A. Gilbert, W. R. Murphy, Jr., T. J. Meyer. J. Am. Chem. Soc. 105, 4842 (1983); (e) J. A. Gilbert, D. S. Eggleston, W. R., Murphy, Jr., D. A. Geselowitz, S. W. Gersten, D. J. Hodgson, T. J. Meyer. J. Am. Chem. Soc. 107, 3855 (1985).

28. R. Manchanda, G. W. Brudvig, R. H Crabtree. Coord. Chem. Rev. 144, 1 (1995). 
29. (a) H. Inoue and M. Hida. Bull. Chem. Soc. Jpn. 55, 2692 (1982); (b) S. Takagi, T. Okamoto, T. Shiragami, H. Inoue. Chem. Lett. 793 (1993); (c) K. Maruo, Y. Wada, S. Yanagida. Bull. Chem. Soc. Jpn. 65, 3439 (1992); (d) K. Maruo, Y. Wada, S. Yanagida. Chem. Lett. 565 (1993); (e) T. Kitamura, K. Maruo, Y. Wada, K. Murakoshi, T. Akano, S. Yanagida. J. Chem. Soc., Chem. Commun. 2189 (1995); (f) T. Kitamura, Y. Wada, K. Murakoshi, M. Kusaba, N. Nakashima, A. Ishida, T. Majima, S. Takamuku, T. Akano, S. Yanagida. J. Chem. Soc., Faraday Trans. 92, 3491 (1996); (g) T. Kitamura, H. Fudemoto, Y. Wada, K. Murakoshi, M. Kusaba, N. Nakashima, T. Majima, S. Yanagida. J. Chem. Soc., Faraday Trans. 93, 221 (1997).

30. J. M. Lehn. Supramolecular Chemistry, VCH, Weinheim (1995).

31. G. L. Geoffroy and M. S. Wrighton. Organometallic Photochemistry, Academic, New York (1979).

32. S. Takagi and H. Inoue. In Multimetallic and Macromolecular Inorganic Photochemsitry, V. Ramamurthy and K. S. Schanze (Eds.), pp. 215-342, Marcel Dekker, New York (1999).

33. J. H. Fuhrohop, K. Kadish, D. G. Davis. J. Am. Chem. Soc. 95, 5140 (1973).

34. H. Inoue, K. Chandrasekaran, D. G. Whitten. J. Photochem. 30, 269 (1985); S. Takagi, H. Morimoto, T. Shiragami, H. Inoue. Res. Chem. Intermed. 26, 171 (2000).

35. (a) J. T. Groves and R. Quinn. Inorg. Chem. 23, 3846 (1984); (b) J. T. Groves and R. Quinn. J. Am. Chem. Soc. 107, 5790 (1985); (c) H. Ohtake, T. Higuchi, M. Hirobe. Tetrahedron Lett. 33, 2521 (1992); (d) W. H. Leung, C. M. Che, C. H. Yeung, C. K. Poon. Polyhedron 12, 2331 (1993); (e) A. S. Goldstein, R. H. Beer, R. S. Drago. J. Am. Chem. Soc. 116, 2424 (1994); (f) W. C. Cheng, W. Y. Yu, K. K. Cheung, C. M. Che. J. Chem. Soc. Chem. Commun. 1263 (1994); (g) P. L. Maux, H. Bahri, G. Simonneaux. J. Chem. Soc. Chem. Commun. 1287 (1994); (h) B. Scharbert, E. Zeisberger, E. Paulus. J. Organomet. Chem. 493, 143 (1995); (i) J. T. Groves, M. Bonchio, T. Carofiglio, K. Shalyaev. J. Am. Chem. Soc. 118, 8961 (1996).

36. (a) T. J. McMurry and J. T. Groves. Cytochrome P-450: Structure, Mechanism, and Biochemistry; P. R. Ortiz de Montellano (Ed.), pp. 1-28, Plenum, New York (1986); (b) D. Mansuy. Pure Appl. Chem. 59, 759 (1987) and references therein; (c) B. Meunier. Chem. Rev. 92, 1411 (1992) and references therein.

37. (a) D. Ostovic and T. C. Bruice. Acc. Chem. Res. 25, 314 (1992); (b) R. D. Arasasingham, G. X. He, T. C. Bruice. J. Am. Chem. Soc. 115, 7985 (1993); (c) T. G. Traylor and F. Xu. J. Am. Chem. Soc. 110, 1953 (1988).

38. S. Funyu, T. Isobe, S. Takagi, D. A. Tryk, H. Inoue. J. Am. Chem. Soc. 125, 5734 (2003).

39. W. H. Leung and C. M. Che. J. Am. Chem. Soc. 111, 8812 (1989).

40. C. J. Liu, W. Y. Yu, C. M. Che, C. H. Yeung. J. Org. Chem. 64, 7365 (1999).

41. J. T. Groves, Y. Han, D. V. Engen. J. Chem. Soc., Chem. Commun. 436 (1990).

42. (a) F. R. Hopf, T. P. O'Brien, W. R. Scheidt, D. G. Whitten. J. Am. Chem. Soc. 97, 277 (1975);

(b) E. M. Vogler and H. Kunkely. Ber. Bunsenges. Phys. Chem. 80, 425 (1976); (c) N. Farrell, D. H. Dolphin, B. R. James. J. Am. Chem. Soc. 100, 324 (1978); (d) M. Hoshino and Y. Kashiwagi. J. Phys. Chem. 94, 673 (1990). 